\title{
A NARRATOLOGICAL APPROACH TO CONTENT SELECTION IN AUDIO DESCRIPTION. TOWARDS A STRATEGY FOR THE DESCRIPTION OF NARRATOLOGICAL TIME ${ }^{1}$
}

\author{
Gert Vercauteren \\ University College Antwerp (Belgium) \\ gert.vercauteren@artesis.be
}

\begin{abstract}
As more and more countries start to provide audio description services for a growing range of products and events, research into this new discipline is growing and diversifying as well. Two questions that seem to be at the heart of much of this research focus on what should be described and how this should be done, in other words on content selection and formulation of the description. The present article looks at the first of these two questions and approaches it from a narratological point of view. After a general discussion of the use of narratology for audio description, the focus will shift to one particular constituent of narrative, namely time. The different temporal aspects will be discussed in greater detail, after which a strategy for the audio description of time in film will be proposed.
\end{abstract}

\section{Résumé}

De plus en plus de pays commencent à offrir des services d'audio description pour un nombre croissant de produits et évènements. La recherche dans cette nouvelle discipline a de ce fait tendance à se développer et à se diversifier. Deux questions paraissent être au cœur de nombreuses recherches : que faut-il décrire et comment faut-il le faire? Ou, en d'autres termes, quel contenu choisir et comment formuler la description? Cet article se penche sur la première question et adopte une approche à partir

1. This article is part of the European Project AD LAB: Audio-description. Lifelong Access for the Blind with reference no. 517992-LLP-1-2011-1-IT-ERARMUS-ECUE. 
d'un point de vue narratologique. Après une discussion générale sur l'utilité de la narratologie à des fins d'audio description, l'accent sera mis sur un composant particulier de la narration: le temps. Les différents aspects temporels seront examinés plus en détails et une stratégie d'audio description du temps pour le cinéma sera proposée.

Keywords: Audio description. Audiovisual translation. Narratology. Content selection.

Mots-clefs: Description audio. Traduction audiovisuelle. Narratologie. Sélection de contenu.

Manuscript received on July 15, 2011; Definitely accepted on November 15, 2011. 


\section{Introduction}

As audio description (AD) as an academic discipline is starting to come of age, research in the field begins to develop in different directions. Two questions that seem to be at the heart of much of this research deal with what has to be described (the content of the audio description) and with how the product at hand should be described (the form of the audio description). To formulate answers to the former question, researchers have turned to different methodologies and disciplines such as corpus analysis (e.g. Jiménez Hurtado 2007; Salway 2007), eye-tracking studies (e.g. Vilaró et al. 2012; Orero \& Vilaró, in this volume) and narratology (e.g. Kruger 2010). Contributions to the field that focus on the second question are based on discourse analysis (e.g. Braun, forthcoming), linguistics (e.g. Rodríguez 2007) or reception studies (e.g. Chmiel \& Mazur 2011), among others.

The present article looks at the first question, i.e. content selection, and evaluates the use of a narratological approach to content selection in audio description. Although some of the insights and strategies presented here are probably valid for various modalities of audio description, such as theatre, opera, and television, the article will only focus on audio description for film. Part one considers the usefulness of narratology for selecting (the most) relevant information to be audio described; part two will focus on one particular narrative building block, namely 'time', and looks at how describers can go about describing this structuring element from a narratological point of view.

\section{The usefulness of narratology for audio description}

\subsection{From guidelines to strategies}

Audiovisual products such as films are inherently multimodal in nature, creating meaning from the combination of and interaction between different semiotic channels: images, dialogues, sounds and text-on-screen. This multimodality undermines the accessibility of these products for some audiences, as can be explained on the basis of the following diagram. 


\begin{tabular}{|c|c|c|}
\hline MODE & + VISUAL & - VISUAL \\
\hline + VERBAL & text-on-screen & dialogues \\
\hline - VERBAL & images & sound effects \\
\hline
\end{tabular}

Figure 1: The different meaning-making semiotic channels of films

Given their visual impairment, blind and partially sighted audiences do not have full access to the two visual channels, making it impossible for them to re-create the entire meaning of the product. Moreover, because films combine the different semiotic channels to create meaning, dialogue turns and sound effects often have a direct link to the images (Baumgarten 2008) and are therefore not always clear to these audiences either. So in order to render films accessible to the visually impaired, the semiotic channels to which they do not have access have to be translated into a mode that is accessible to them, i.e. the verbal mode. However, this type of intersemiotic translation is far from unproblematic.

There are at least two fundamental differences between visual communication and verbal communication that complicate the audio description process. First of all, visual communication is more implicit than its verbal counterpart (Sperber \& Wilson 1995), making it sometimes hard to determine what exactly is being communicated. In other words, there will be instances where audio describers will find it difficult to determine the precise visual content they have to include in their verbal description. Moreover, visual communication presents information simultaneously, whereas a verbal translation of this information can only be presented sequentially (Kress \& Van Leeuwen 1990) and thus takes (much) more time to render. Because audio descriptions can only be inserted in the audiovisual product when there is no dialogue or meaningful sound effect - a constraint imposed by all existing $\mathrm{AD}$ guidelines - there will sometimes not be enough time to describe everything shown on screen, obliging the describer to select only the most relevant pieces of information. These two difficulties might explain why the question of content selection has received so much attention in AD literature so far.

The first body of documents in which the problem of what to describe was addressed and rightfully characterized as "one of the hardest questions for a describer" (Greening et al. 2010: 4) are AD guidelines. From a comparative study of existing guidelines carried out by the RNIB we learn that they are in agreement about what has to be described, namely 'when, where, who and what' (ibid., 4), but neither the comparison nor the actual guidelines in the appendixes really discuss content selection in depth or tell describers how to 
prioritize information. It is by no means the objective of the present article to explore all the merits and shortcomings of the guidelines and one might even question the use of this kind of discussion. There are, however, two issues that seem to be relevant in the framework of the present article. First, the guidelines never mention why you have to describe the elements they mention, i.e., they are rather intuitive and lack any form of theoretical grounding. In addition, they are either very general, stating what has to be described in one single paragraph, such as the Spanish UNE 153020 Standard (ibid., 16), or very specific, focusing on some particular elements such as colour or ethnicity, but not on others. So although the guidelines may be useful as a first introduction to what to describe, a truly valid aid to content selection in $\mathrm{AD}$ should be based on a solid theoretical framework and offer strategies that are general enough to be used in different film genres but specific enough to be applied to individual scenes.

\subsection{A better understanding of how stories are told: basic insights in narratology}

When looking for a solid theoretical basis for content selection in audio description, one possible candidate that seems to offer various advantages is narratology. A first advantage has to do with the source product. Bordwell and Thompson write that films take us through experiences that are often driven by stories (Bordwell \& Thompson 2008: 2). So a theory offering insights into how these stories are created and how the medium signals what is narratologically most relevant, can be helpful for describers who have to recreate the filmic experience in a semiotic system that does not always allow them to include all the information they would want to.

When looking at the intersemiotic translation process that is audio description, a question that arises is whether stories in a multimodal medium such as film are told according to the same principles as in a 'unimodal' verbal system. In other words, is there some kind of one-to-one equivalence allowing audio describers to translate visual narrative information into verbal narrative information? The advantage narratology offers in this respect, is that the theory has been developed for both visual narrative and written narrative, allowing us to make a comparison between these two forms of narrative and analyse what principles are the same and what differences the describer of film narratives has to take into account.

As in any other translation process, the describer plays a dual role. Not only is he the author of the audio described target product; he is also a member of the audience of the source product. An advantage that narratology seems to offer in this respect is that it studies narratives both from a more 
author-centred, story-creation perspective (structuralist narratology) and from a more audience-oriented, story-reception perspective (cognitive narratology). For audio description, both fields are useful. Structuralist narratology tells us what different narrative constituents or 'building blocks' authors can use to create their stories (i.e., it focuses on the content of our content selection process). Cognitive narratology on the other hand tells us how audiences process stories and how they prioritize information (i.e., it focuses on the selection of our content selection process). Together they can help clarify the double role and task of the describer.

In the present article we will focus mainly on structuralist narratology or story creation, examining the different constituents authors use to design their stories in general, and elaborating one of these constituents, namely time, in more detail. Before turning to the specific components of narrative, however, a short introduction to the general narrative creation process or the 'narrative constitution' to use Wolf Schmid's term (Schmid 2005), may prove to be useful. Based on earlier work by the Russian formalists, structuralist narratologists make a distinction between the physical narrative product an audience is presented with and the underlying abstract levels (Herman \& Vervaeck 2005: 41) that reflect the different transformations stories undergo during their creation process, as we will briefly explain in the next paragraphs. Although most authors agree that narratives consist of two or three levels, the starting points for their categorizations are often different and hence they use quite different terms to label them or attribute different meanings to homonymic terms (Scheffel 2010: 4). In the remainder of the article, we will use the terminology as developed by Bal in her Narratology. An Introduction to the Theory of Narrative (1995).

The first and most basic level of a narrative is an abstract construct in which the narrative events are presented in the logical order in which they would normally take place in the real world. The actants involved in those events are equally abstract 'roles' without any physical or psychological characteristics. This level is what Bal with a formalist term calls the fabula, a concept she defines as "a series of logically and chronologically related events that are caused or experienced by actors" (Bal 1995: 5). As becomes apparent from this definition, the main focus on the fabula level is on the temporal relations between events: they are presented in the chronological order in which they happen, which is not always the order in which they are presented in the actual narrative the audience will receive. And although these temporal relations are narratologically very important, as we will discuss in the next paragraph, one other dimension of time is completely absent from Bal's definition: 
all these events take place in a specific setting, which itself consists of a spatial component and a temporal component. It is true that in written fiction, this temporal dimension can be absent or left very implicit, but in film, unless the scene takes place in an interior space without any visual connection to the outside world or any other indication of time, e.g., in the form of texton-screen, we always get some indication of the temporal setting, such as the time of day or year, weather conditions, etc. It is important that audio describers be aware of these two dimensions, as we will discuss later.

The second level of the narrative constitution is what Bal calls the story level, defined as "a fabula that is presented in a certain manner" (Bal 1995: 5). On this level, the three basic constituents of the narrative - time, space and characters - all undergo various changes and adaptations that are all clearly motivated. On the level of the temporal relations between events, the author determines their order (whether he will present the events in his narrative chronologically or not), their frequency (how often they will be presented) and their duration (whether or not they will be presented at another 'speed' than the regular, real-life speed). In the second part of this article, we will discuss these three concepts and their functions in greater detail, but one example might clarify the author's options and their possible meaning for the narrative.

The film Slumdog Millionnaire tells the story of Jamal Malik, an 18-yearold orphan from the slums of Mumbai who is one question away from winning 20 million rupees on the game show Who wants to be a Millionaire. However, when the show is interrupted for the night he is arrested because the police suspect him of cheating. During the interrogation, he watches the show from the previous night with a police officer and with every question he tells a part from his earlier life that explains how he knows the answer to this question. A chronological account of all these facts would start with all the episodes from his childhood and end with the game show and Jamal's arrest. However, the film starts with the arrest, then goes back to the game show and the different questions Jamal has to answer. All these questions are then interrupted by flashbacks to earlier moments in Jamal's life. This anachrony serves various purposes. First of all, starting with the last event (i.e., Jamal's arrest) immediately arouses the audience's curiosity: why is this boy arrested? Alternating the scenes at the game show with flashbacks to events in Jamal's earlier life, has a double purpose: on the one hand, they explain why he knows the answers to all the questions, on the other hand they create suspense by postponing the answer to the question everybody in the audience has, namely will he ultimately win those 20 million rupees. In other words, by changing the 
chronological order, the author can create suspense, and generate curiosity and surprise. Moreover, by inserting flashbacks that explain events that take place in the narrative present, he can clarify the story.

Furthermore, the story level is the stage at which the author, in this case the filmmaker, concretizes the setting of the events taking place. In other words, he specifies the temporal circumstances (historical period, season, time of day, weather conditions, etc.) and decides whether a specific spatial frame will function as a mere background or will have a symbolic meaning, whether the frame is to be static or dynamic and whether it is open and thus connected to other frames, or closed. He will decide what the particular contents of the spatial frame will be and will develop the relations between space and time and between spatial frames and the characters in them. Good examples of the possibilities and choices open to directors on the spatial level can be found in Shutter Island. The film tells the story of U.S. marshal Teddy Daniels, who investigates the disappearance of a murderess who escaped from a hospital for the criminally insane that is located on the Boston Harbour Islands. The location chosen for this movie, i.e., a secluded island, is more than a mere background. It has a very clear motivation and a highly symbolic meaning. First of all, just like the temporal example from Slumdog Millionaire, the space generates an intriguing question for the audience right from the start: how can somebody disappear and escape from an isolated island? The problematic nature of an escape from a 'closed spatial frame' causes curiosity and suspense from the very beginning of the movie. Also the contents of the frame, i.e., the topography of the island, are very well chosen and add to the suspense. One side of the island is covered in ominous woods, the other ends in steep cliffs, adequately described by the captain of the ship that brings Teddy to the island: "The other side of the island is rock bluffs, all the way down to the edge of the water." With his next sentence: "The dock is the only way on... or off. We'll be casting off as soon as you [two] are ashore", he emphasizes the isolation of this 'closed frame'. Again, by choosing a specific frame, giving it a clear meaning and filling it with the right content, the author can create suspense or arouse the audience's curiosity (cfr. Scheffel 2010).

It is also on the story level that abstract actors are turned into real characters: they are given unique physical features that distinguish them from other characters in the narrative; their communicative and behavioural dimension is developed, determining what acts they will perform; and the necessary psychological traits to motivate those actions are created (cfr. Remael \& Vercauteren 2007). A good example of this 'characterization' of abstract actors can be found in Law Abiding Citizen, the story of engineer Clyde Shelton, whose 
wife and daughter are brutally murdered by two burglars. When Shelton feels he is betrayed by the legal system because one of the two burglars is acquitted after making a deal with the prosecutor, he decides to take justice into his own hands. This frustration, combined with the fact that he has always been a law abiding citizen, as the title suggests, is the main character trait that motivates Shelton's retaliatory actions later on in the movie. The profession that he was given by the author, together with the supposed intellectual capacities it requires, motivate the way in which he carries out these actions, namely by designing and constructing bombs and other advanced devices to kill his opponents.

As these three examples show, the story level is where the most important narrative-shaping decisions are taken. This is where the author arouses curiosity, generates suspense and creates surprise, and where he decides what traits characters need to motivate their actions.

The third level of the narrative constitution, following fabula and story, is the narrative text, "a text in which an agent relates ('tells') a story in a particular medium, such as language, imagery, sound, buildings, or a combination thereof" (Bal 1995: 5). The narrative text is the actual physical level of the narrative constitution. It is at this level that the author decides by means of what techniques he will show all the choices he has made on the story level. Will a director of a film present a flashback by means of a fade-out or wipe, or will scenes that take place earlier in the fabula be presented in black and white? Or instead of showing this anachrony in an explicit manner, will he leave it more implicit by showing the characters at a younger age or will he resort to a mere scene change without any indication of time? Will the threatening atmosphere of a space be rendered physically, by presenting it as a small, confined place, or through the use of dark colours? Or will the director turn to the other semiotic channels in the medium and combine the images with ominous music? And how will he clarify what motivates the characters' actions? Will it be shown through specific body movements, a close-up of a facial expression, or again via another semiotic channel (sound or dialogue)? All these and many other choices will determine what specific narrative text the audience will finally be presented with.

But not only do these choices define the ultimate narrative text; all the visual, verbal and other aural cues the audience is presented with, also determine how they will re-create the initial fabula. Briefly, while the author of a narrative text starts from the chronological fabula, determines how he will present time, space and characters on the story level and then decides what techniques he will use to externalize them in the physical narrative product, 
the audience will work in exactly the opposite direction. They are first presented with the textual cues and will use these indications to evaluate the author's choices (why was a flashback used here, what physical or psychological trait motivated this character's action, why is that room suddenly presented as a threatening space, etc.) and ultimately recreate the initial fabula (see Figure $1)$.

As shown in Figure 1, the audio describer plays a double part in this construction and reconstruction of narrative texts, and as such has a rather complicated task. As a member of the audience of the original narrative text, he will have to reconstruct the initial fabula. This means he will first have to pinpoint all the different cues (and their meaning) offered in the concrete narrative and work out what motivated the different choices the author made on the story level. As the author of the audio description of the narrative text, he will have to make sure that the blind and partially sighted audience has access to all the narrative elements necessary to recreate the fabula the original author started from. In other words, he will have to offer sufficient cues to allow the audience to determine what the temporal setting of a particular scene is and what the temporal relations between consecutive scenes are. Likewise the visually impaired audience must be able to recreate the spatial setting, atmosphere and relations from the description and must acquire enough insight into the characters' physical, behavioural and psychological dimensions to figure out what they look like, what they do and what motivates their actions.

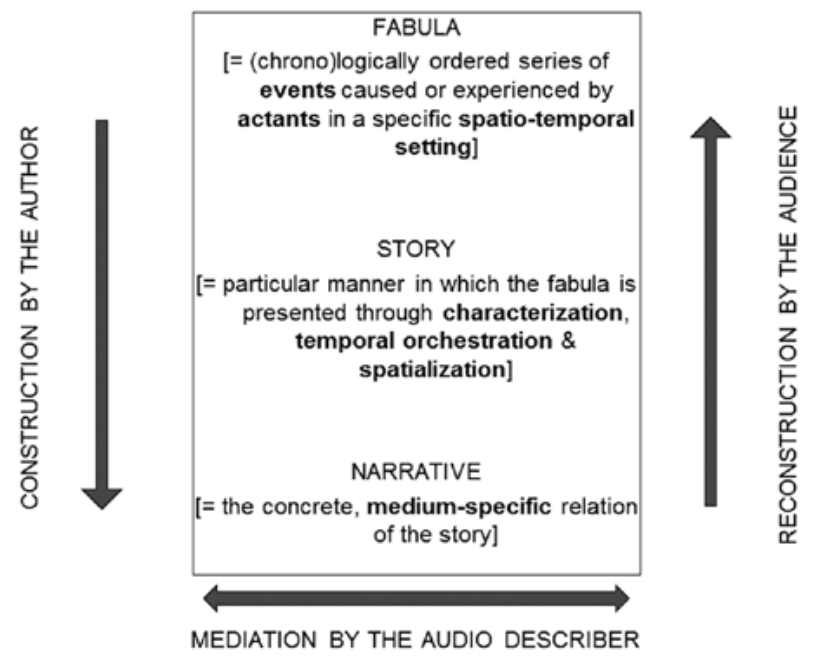

Figure 2: Construction and reconstruction of narrative texts 
To accomplish this, the describer first scans all the scenes for the different cues relating to the narrative's basic constituents, i.e. time, space and characters, and determines what cues the blind and partially sighted audience can access through the other (aural) semiotic channels in the film, as well as what the audience knows from the context. In addition he will have to determine the level of explicitness of the visual cues that are possible candidates for description: elements that are explicitly shown (e.g., a text on screen indicating a time, an image of the Eiffel Tower) can be described explicitly, elements presented in a more implicit way (e.g., a shot suggesting that a character is being watched, an ambiguous facial expression) will have to be described in more 'masked' terms, and cues that are absent or unclear for the sighted audience (e.g., the exact location of a scene, or the temporal relations between consecutive scenes) can be left out of the description. Although this last observation may seem obvious and trivial, it is worth mentioning because it may help (beginning) describers to discard certain elements from their descriptions in an early stage of the script writing process when pressed for time. Next, the describer will have to decide what cues will be described and how they will be formulated so that the original fabula can be reconstructed and (as far as possible) an experience is created that is more or less equivalent to the sighted audience's.

It would be impossible to explore all these different stages in the $\mathrm{AD}$ script writing phase in detail in this article, or even to discuss the three basic narrative constituents. Therefore, the next part will focus exclusively on the temporal component of the narrative. The different dimensions and constituents of narratological time mentioned above will be explored in more detail, and I will then try to translate this theoretical background into a strategy that can be used by audio describers for the description of narratological time.

\section{Time in Structuralist Narratology}

The following paragraphs look at the different temporal aspects in narrative and will discuss whether or not, and in what instances, they need description. In other words, I will only look at the 'what' or content selection question; the question of how they should be described, will be left out of consideration. When looking at the different basic constituents of a narrative, time seems to be by far the easiest to analyse systematically from a structuralist point of view. It is true that it is much clearer and more unambiguous than characters or space. Indeed, Zoran (1984: 310-312) discusses the problems underlying the concept of space at length and Bal (1995: 132) agrees that "few concepts from the narrative text are as self-evident and have yet remained so vague 
as the concept of space". With regard to characters, Herman and Vervaeck (2005: 70) note that "[O]bviously, it is not at the level of character analysis that structuralist narratology has made its most significant contribution". On-going research has shown that structuralist narratology can offer a sound basis for the definition of the basic constituents of narrative characters and space (Vercauteren 2010a, 2010b) but much more input from the cognitive field is needed to make the appropriate selections, given the myriad of different subcomponents making up the character and spatial dimensions of a narrative text. Time, as will become apparent in the next paragraph, is much more clear-cut.

\subsection{Temporal Settings of Narratives}

As mentioned before, the temporal constituent of a narrative text consists of two narratological dimensions. First, there is the temporal dimension of the setting that is indispensable for any narrative to exist and that is intrinsically linked to the spatial component of the setting, as becomes apparent, for example, when looking at the terminology used by narratologists. Bakhtin (1981) uses the term chronotope or 'spacetime', and Herman and Vervaeck (2005) define setting as a 'spatio-temporal' indication in which events take place. It seems to be the case that, in visual communication probably even more than in verbal communication, the two cannot be separated from each other. Every outside scene in a film shows a place and gives an indication of time, and even in many inside scenes the two are made explicit or can be inferred from implicit cues. So although we consider time as a separate element in this article, describers have to be aware that it cannot be separated from the spatial component and that they must make sure that the complete spatio-temporal setting is clear to their blind and partially sighted audience, whenever it is to the sighted audience.

In his doctoral dissertation on the spatio-temporal setting in written narrative fiction, Pitkänen (2003) discusses so-called time-oriented settings in depth, presenting three different elements that can be considered to be indications of time in narrative. The first one he mentions is grammatical tense, an important marker in written narrative, but less so in audiovisual narratives such as films. Grammatical tense obviously plays an important part in creating temporal settings that are recounted in the dialogues of a film. However, for audio describers, whose main focus is on the visual, it is less crucial. The other two elements, however, apply to both written and visual communication. On the one hand, there are purely temporal markers (mentions of a specific era, season, time of day), on the other, there are all the biographical, 
socio-cultural and historical references that give an indication of the time period in which the narrative is set. This last distinction is again an interesting one for audio describers, as it seems to indicate that there are different degrees of explicitness with which time can be expressed in narrative. In film, for example, captions on screen are the most explicit renderings of the temporal setting. There are also purely visual temporal markers, but except from clocks, calendars and other visual aids giving a precise time indication, those markers are already more implicit (snow typically refers to winter, but can probably also indicate late autumn or early spring; a dark setting can indicate that it is night, but also late evening or early morning, etc.). Even more implicit from a temporal perspective are Pitkänen's biographical, socio-cultural and historical references. They require more inferring by the audience to determine the actual time period they represent and, in addition, the describer will have to judge whether his audience has the necessary extra-textual world knowledge to infer this time period from the description of the actual reference, or whether they need a more explicit time indication.

Further, Pitkänen (ibid.) distinguishes between global time and local time, the former being the general time period in which a narrative is set, the latter being the time frame of a specific scene. Translated for audio description, this would mean that the describer has to make sure that his audience knows in what time period(s) the film is set (either from a description of an explicit time reference such as a date shown on screen, or from more explicit cues such as specific buildings, people or objects referring to a specific time period), and that they know what the temporal frame of every individual scene is. So for every new scene, he will have to determine whether the global or local time has changed and if so, point this out in his description.

\subsection{Temporal Orchestration}

In addition to the temporal dimension of the settings in a narrative there is a second, equally important time aspect, namely the temporal relations between (consecutive) scenes. In his seminal work on narrative time, Genette (1972) uses three criteria to structure the different temporal relations in a narrative: order, frequency and duration. These criteria have been discussed in detail both for written narrative (e.g. Bal 1995: 78-113; or Herman \& Vervaeck 2005: 60-67) and for filmic narrative (e.g. Bordwell 1985: 74-98), so in the present article, we will only focus on the aspects that are most relevant for audio describers. One preliminary remark to be made here is that, in an audiovisual medium such as film, the three different aspects mentioned above can be rendered both verbally and/or visually, two possibilities Bordwell 
(1985: 78) calls recounting and enactment. In case of a character talking about an event that is simultaneously shown on screen, we talk about enacted recounting (ibid.). In the cases of recounting and enacted recounting, there is no time for description, so it is only in the cases where events are enacted, that the audio describer has to provide the necessary temporal cues (as always, if they are explicit enough to be inferred by the sighted audience).

\subsubsection{Order}

On the fabula level, the events that take place are presented in their chronological order, but this need not be so on the level of the physical narrative text. The order in which the events are ultimately shown, can be changed for various reasons; the director might for example use a flashback to explain what motivated a certain action by one of the characters in the narrative present. He may use a flashback to deliberately delay information and create gaps in the narration to evoke suspense or curiosity, etc. Bordwell (1985: 77) distinguishes between four different possibilities, four different relations between the order in which events occur in the fabula and the order in which they are presented to the audience in the narrative text. I will discuss them briefly below, detailing the implications they may have for AD.

a) two events that occur simultaneously in the fabula are presented simultaneously in the narrative. This can be the case in split-screen scenes where simultaneous events are shown on different halves of the screen or in deep-space compositions where actions take place in the background while something is happening in the foreground as well. Because this simultaneous visual representation can never be rendered simultaneously in a verbal description, as explained in chapter 2, this possibility might constitute a problem for the describer when there is little time for description and an ad hoc solution may have to be found;

b) two events that occur successively in the fabula are presented simultaneously in the narrative. This is rare in film, as Bordwell (1985: 77) also points out. This might happen for example when an off-screen voice talks about prior fabula events while images about present events are shown. In these instances, there will be no time for description given the presence of a verbal component. Another possibility is that characters in the narrative present watch a video in which prior fabula events are shown. If in this case characters discuss the images that are shown on the video, there is again a verbal component and no 
time for AD. If however, the scene is purely visual, the audio describer should try to make clear that the different events that are shown at the same time, take place in two different time periods;

c) two events that occur simultaneously in the fabula are presented successively in the narrative. The typical example of this possibility is cross-cutting. Because of the successive presentation, this possibility will presumably create fewer problems for the audio describer unless there is little or no time for description because of dialogue sequences or other verbal components. Although different description techniques could be used to indicate the simultaneous occurrence of the fabula events, a recent analysis by Remael and Vercauteren (2010: 162-165) of a small corpus of audio described films seems to indicate that describers most often turn to the conjunction 'as' to render this simultaneity. Likewise, Salway (2007: 165) concludes from his corpus analysis that both 'as' and 'while' are most used to indicate simultaneity. Caution is in order, however, because cross-cutting does not only relate to simultaneous fabula events (Bordwell 1985: 84). Indeed, it can also be used to switch between successive events. In other words, the describer will have to keep this in mind and evaluate whether we are dealing with cross-cutting employed to narrate simultaneous or successive fabula events. In this last case, descriptions using 'while' or 'as', could create a false idea of simultaneity;

d) two events that occur successively in the fabula are presented successively in the narrative. This is the typical situation in film, but it is also in this instance that the director has the most options to play around with their order. He can decide to maintain the chronology of the events from the fabula, in which case no reference to the order of events has to be made in the AD because this is the order the audience would naturally presume. ${ }^{2}$ However, he can also decide to show

2. It would go beyond the scope of the present article to discuss the audience's cognitive processing of narratives at length. The claim made here, can for example be found in Toolan's contribution on coherence to The Living Handbook of Narratology (http://hup. sub.uni-hamburg.de/lhn/index.php/Main_Page), stating: "Addressees 'naturally' attribute relevance and coherence to any text or discourse until evidence to the contrary is overwhelming. Echoing Grice (1975), they argue that a rational assumption of relevance has shaped any speaker's (or writer's) contribution. Where an utterance's relevance, orderliness, informativeness and truthfulness is not obvious, a search for their covert presence is warranted. A corollary of this is that a speaker or writer can be assumed to be continuing to speak or write of the same spatiotemporal setting and the same characters, unless a change is explicitly signaled." (Toolan 2010: 13). 
successive events out of their chronological order, showing the most recent fabula event first and showing an earlier event later, as in the Slumdog Millionaire example. In this case a description pointing out this anachrony would make sure that the blind and partially sighted audience knows that the events shown are not chronological. An additional difficulty for describers here is the level of explicitness of the time change. Directors can indicate anachrony in a very explicit way, for example with a text-on-screen indicating that we are in a different time period. However, flashbacks can be introduced in much more implicit ways too. This too, should possibly be reflected in the description.

\subsubsection{Duration}

With regard to duration, Bordwell (1985: 80-88) distinguishes between the duration of an event or series of events in the fabula, their 'dramatized' duration in the filmic narrative ('story duration in Bordwell's terminology) and their more technical duration on screen. For example: all the events taking place in Slumdog Millionaire span a period of approximately 14 years in the fabula. The filmic narrative only shows 2 days of Jamal Malik's life as an 18-year old boy and a few days from his earlier life. All these moments are shown on screen in 120 minutes. In other words: on the level of the whole film, the fabula time will usually be longer than the story time, which in turn will usually be longer than the screen time. Yet this is a generalization and the differences between these three types of duration might be very small (e.g. the action series 24) or much larger (e.g. Slumdog Millionaire). For the durational aspect, Bordwell discusses three possibilities:

a) Equivalence: fabula duration, story duration and screen duration are essentially equal. On the level of individual scenes, this is the most common situation in film; the temporal aspect, i.e., this equivalence in duration, does not need description because again this is what the audience would naturally expect.

b) Reduction: fabula duration is greater than story duration, which can be greater than or equal to screen duration. This is the most common situation on the level of the whole film, as mentioned above. On the scene level, two further distinctions can be made:

- Ellipsis: some fabula events or parts of those events are left out of the filmic narrative and/or on screen, creating narrative gaps. Although existing guidelines indicate that you should only describe 
what is shown on screen, I think this point should be refined in the case of ellipsis. In the opening scene of the film Derailed for example, we see the main character lying in bed. In the next shot, he is sitting at the breakfast table. The fabula events of him getting dressed and walking to the kitchen are not shown on screen, presumably because they are narratively irrelevant. In this case the guidelines can be adhered to and no description of this ellipsis is needed, leaving more time for description of elements that are relevant. In Memoirs of a Geisha we encounter an ellipsis of a completely different nature. In a first shot, a young girl is praying in a temple, presumably somewhere in spring, as all the cherry trees are in bloom. The next shot takes us outside, showing cherry blossoms falling from the trees and drifting through the air. The camera then tilts upward first showing the cherry blossoms but then snow falling from the sky, indicating that seasons have changed. The next interior shot shows that we are actually many years later and that the young girl has now grown up. As we are dealing with an ellipsis that is narratologically relevant, this is an instance where the describer would have to evaluate whether his audience can infer this gap from descriptive verbal cues or whether it needs to be included in the description more explicitly;

- Compression: the events from the fabula and the filmic narrative are presented in an 'accelerated' way on screen, for example through fast-forward or montage sequences. Like in the case of ellipsis, this acceleration can be irrelevant, if no narratively important information is left out. But sometimes the director aims at a stylistic effect when he chooses to use a fast-forward or montage sequence. Existing guidelines, however, give describers the advice not to use technical language in their description, i.e., not to use words like 'fast-forward' or 'montage sequence'. One possible solution to this problem is offered by Thompson, who points out that modern films often use techniques to achieve a certain stylistic effect, but that "style's most fundamental function is to promote narrative clarity" (Thompson 1999: 19). It would then be up to the describer to pinpoint this narrative function and to evaluate if and how it should be included in the description.

c) Expansion: fabula duration and/or story duration are shorter than screen duration. This expansion can be achieved by inserting nondiegetic material in the film (insertion) or by stretching out the fabula 
events on screen, e.g., through overlapping editing or slow motion (dilation). In the case of insertion of non-diegetic elements, the expansion will become apparent to blind and partially sighted viewers from the description of those elements. The case of overlapping editing and especially slow motion is more difficult. In many cases, this expansion of fabula duration is more than a mere effect created by the director for stylistic purposes (cf. compression). Again, it will be part of the describer's task to retrieve the director's narratological intentions and see if they can be included in the description instead of the technical or stylistic feature shown on screen. In other words, in this last case there will often be no description of an actual time element, but rather of another narratologically relevant item.

\subsubsection{Frequency}

Frequency refers to the number of times a fabula event is presented in the narrative text. Bordwell (1985: 79-80) distinguishes between nine different possibilities (cf. figure 3). A fabula event can be presented 0,1 or more than 1 time in the narrative text, and this can be done either through enactment or through recounting:

\begin{tabular}{|l|c|c|c|c|c|c|c|c|c|}
\hline Number of times a fabula event is & A & B & C & D & E & F & G & H & I \\
\hline Recounted & 0 & 0 & 0 & 1 & 1 & 1 & +1 & +1 & +1 \\
\hline Enacted & 0 & 1 & +1 & 0 & 1 & +1 & 0 & 1 & +1 \\
\hline
\end{tabular}

Figure 3: Number of times fabula events are presented in the narrative and how (Bordwell 1985:79)

This temporal element does not really constitute a big problem for describers. If events are not recounted or enacted (value $=0$ ), then obviously no description has to be / can be given. In cases in which events are recounted once or more than once, the describer has no option but to let the dialogue prevail and no description can be inserted. The blind and partially sighted audience will have to infer from the dialogue that a character is talking about a new event (recounted value $=1$ ), or is talking again about a certain event (recounted value $=+1$ ). In cases where events are enacted once (enacted value $=1$ ), the describer will insert a description for that event. If that event is enacted again later (enacted value $=+1$ ), the describer will have to determine whether it is presented in exactly the same way or if the event is presented in a (slightly) different way (e.g. events as seen by another character, flashback to a scene shown earlier, but with new details, etc.). In that case, his description 
will have to indicate that we are dealing with the same event and that, if applicable, new elements are presented.

In conclusion: as far as temporal relations between scenes are concerned, the audio describer will have to consider three different aspects, namely order, duration and frequency. In some of these cases, no audio description is needed, that is, when it is an instance that an audience would presume as being natural or logical (e.g., two consecutive scenes being shown in their chronological order, a fabula event presented on screen for its normal duration, etc.). In other instances, where events are shown out of their chronological order, when slow-motion or fast-forward is used or where a certain event is shown more than once, the describer has to indicate this temporal 'abnormality' (or its narratological function) in his description. The next question is: can these different possibilities be translated into a strategy that can be applied to any scene in a movie? In the next part, we will try to provide a first tentative answer to this question in the form of a schematic model for the audio description of time.

\section{Towards a strategy for describing narratological time in film}

From the discussion above, it is clear that the describer has to take into account a lot of different elements when creating a description of the temporal constituent of a narrative. For every scene, he will have to look at both the temporal setting and the temporal orchestration or temporal relations. He will have to ask different questions in order to determine what elements need description and what elements can be left out, either because they are not clear to the sighted audience or because they can be inferred from the other semiotic channels in the scene. After having analysed the first scene, he will then have to look at the following scene and determine what has changed from a temporal point of view (and possibly needs description), and what has remained the same (and does not necessarily need to be described again). Schematically, this decision making process could be presented as follows:

In this workflow, the describer starts with the first scene and looks at the temporal setting. If the setting (local and/or global time) is not clear to the sighted audience, because no explicit time reference is given or there are no biographical, socio-cultural or historical references to a specific time, no audio description is needed. ${ }^{3}$ If the setting is clear, the describer can describe

3. There currently is a discussion within the field of AD research about the amount of audience participation wanted in AD. Some say the blind and partially sighted should make the same inferences as the sighted audience (i.e. if the sighted audience doesn't know, 


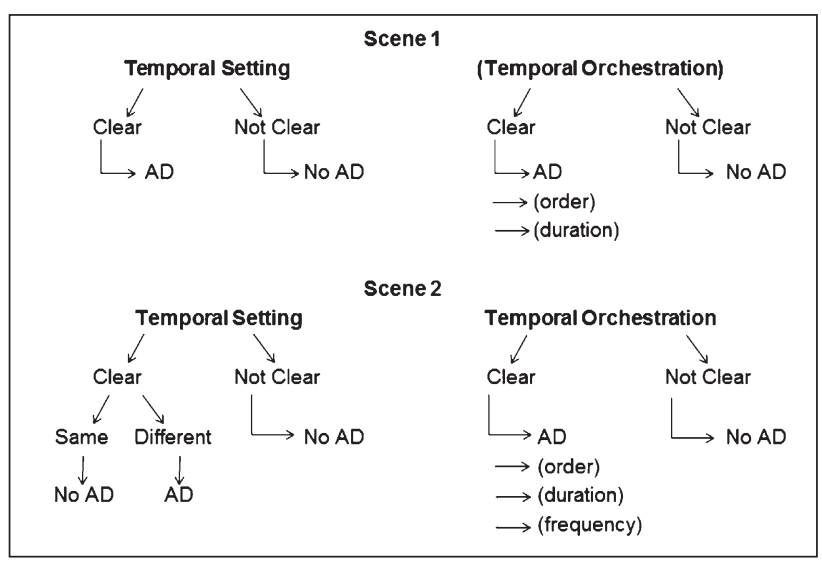

Figure 4: The audio description of narratological time - a schematic model

the local and/or global time, taking into account the level of explicitness of the temporal marker. Furthermore, he should look at the temporal relations ${ }^{4}$ within this scene. If 'Scene 1 ' is understood to be the very first scene of the film, there will more often than not be no temporal relations yet. It will by definition be the first time the scene/event is shown, which explains why 'frequency' is not included under 'Temporal Orchestration' of Scene 1. With regard to the order of events in Scene 1, only simultaneous presentation [cf. cases a) and b) in section 3.2.1]; successive presentation [cases c) and d)] is not possible because it requires at least two scenes. If the scene is shown in slow-motion or fast-forward (durational aspect), the describer should

it shouldn't be explained in the AD). Recent research (Fresno 2011), however, seems to indicate that processing aural information requires a higher cognitive load (and is less well remembered) than visual information, which could mean that a higher degree of explicitation is warranted to decrease the cognitive load required for processing the description. Moreover, as explicitation is generally recognised as one of the universals of translation (Laviosa-Braithwaite 1998: 289) it should come as no surprise that the technique is used in audio description as well, especially since it deals with translation from (a more implicit) source text to a (more explicit) target text. Hence, we will not claim that if a certain temporal aspect is not clear for the sighted audience, it cannot be described. Rather, we suggest that it can be left out of the description, if for example other narratologically relevant elements are clear and should thus get priority. Should there be enough time to include the unclear temporal element and if the describer deems a description necessary to increase understanding, it can be included.

4. 'Temporal orchestration' under Scene 1 and the elements covered by this orchestration, both under Scene 1 and Scene 2, are in brackets, meaning they can possibly be present but do not necessarily need to be. 
evaluate the relevance and importance of this presentation and decide if and how it is to be included in the description.

After both the temporal setting and orchestration of Scene 1 are analysed and (narratologically) relevant decisions regarding their inclusion in the description have been made, the describer can turn to Scene 2. Although the content selection process for Scene 2 closely resembles that for Scene 1, there are a few differences. First, the describer will have to analyse whether there are any changes in the setting (local and/or global time) compared to the previous scene. If there are no changes, description of the temporal setting is not necessary and the audience will assume that nothing has changed. If the temporal setting did change and this change is clear to the sighted audience, the changed local and/or global time can be described, taking into account the level of explicitness of the temporal marker. If the change is not clear to the sighted viewers, then again, description is not necessary. As for Scene 1, the describer will also have to look at the temporal relations. With regard to the relation to the previous scene, he will have to determine whether the chronological order of events is disrupted and evaluate whether or not this has to be included in the description (is it clear to the sighted audience?; can it be derived from the other semiotic channels?). The same goes for the duration and the frequency of the scene, if applicable.

Although this model seems to cover all possibilities with regard to temporal setting and temporal orchestration in (visual) narratives in theory, a necessary next step will be to test it and see if it works in practice. The first limited tests with AD students seem to indicate that it does indeed help them in their content selection, but more research is definitely needed to confirm these first findings.

\section{Conclusion}

This article started from the observation that the question of content selection receives a lot of attention in current $\mathrm{AD}$ research. Existing guidelines do offer some basic help, but strategies with a solid theoretical underpinning that can be applied to all situations, are indispensable. When looking for possible candidates for this theoretical basis, narratology offers various advantages. It is studied both for visual and written narrative, respectively the source and target products of $\mathrm{AD}$, and from a more author-centred and a more audiencecentred perspective, which reflects the dual position the describer occupies. The elaboration of a strategy for one specific component of the narrative, i.e. time, seems to confirm that narratology can be a valuable aid for both $\mathrm{AD}$ practice and $\mathrm{AD}$ research. Many questions remain, however, opening up 
various avenues for further research. Is the strategy developed here, applicable to all scenes? Is narratology equally useful for developing strategies for space and characters, the other basic constituents of the narrative? And can better insights into contextual frames help describers with the problem of content selection? One thing seems to be clear: the development of strategies that are widely applicable, and can be formulated in straightforward rules like the ones given above, will help beginning and more advanced describers create descriptions that are closer to the narrative the director initially wanted to tell.

\section{References}

BAKhtin, Mikhail. (1981) "Forms of Time and of the Chronotope in the Novel." In: Holquist, Michael (ed.) The Dialogic Imagination. Four Essays by M. M. Bakhtin. (Transl. by Caryl Emerson and Michael Holquist). Slavic Series, no. 1. Austin \& London: University of Texas Press. pp. 84-258.

BAUMGARTEN, Nicholas. (2008) "Yeah, that's it!: Verbal reference to visual information in film texts and film translations". Meta 53:1. pp. 6-25.

BAL, Mieke. (1995) Narratology. Introduction to the Theory of Narrative. $2^{\text {nd }}$ edition. Toronto: University of Toronto Press.

BORDWELL, David. (1985) Narration in the Fiction Film. Madison: The University of Wisconsin Press.

BORDWELL, David \& Kristin Thompson. (2008) Film Art: An Introduction. $8^{\text {th }}$ edition. New York: McGraw-Hill.

BRAUN, Sabine. (forthcoming) "Creating coherence in audiodescription". Meta

CHMiel, Agnieszka \& Iwona Mazur. (2011) "Taking Stock of Audio Description Preferences in Poland: A Reception Study". Paper presented at the $4^{\text {th }}$ International Media4All Conference, 28 June - 01 July 2011, London.

Eмmoт, Catherine. (1997) Narrative Comprehension. A Discourse Perspective. Oxford: Clarendon Press.

Fresno, Nazaret. (2011) "Going Cognitive. The Role of Memory in Audio Description". Paper presented at the $4^{\text {th }}$ International Media4All Conference, 28 June - 01 July 2011, London.

GenetTE, Gérard. (1972) "Discours du récit: Essai de méthode." Figures III. Paris: Seuil. pp. 65-282.

GREENING, Joan et al. (2010) A Comparative Study of Audio Description Guidelines Prevalent in Different Countries. London: RNIB Media and Culture Department.

Herman, David. (2002) Story Logic. Problems and Possibilities of Narrative. Lincoln: University of Nebraska Press.

HERMAN, Luc \& Bart Vervaeck. (2005) Handbook of Narrative Analysis. Lincoln: University of Nebraska Press. 
JANNidis, Fotis. "Character". In: Hühn, Peter et al. (eds.) The Living Handbook of Narratology. Hamburg: Hamburg University Press. Available at: hup.sub.uni-hamburg.de/lhn/index.php?title=Space\&oldid=1502 [retrieved 14 June 2011].

JimÉNEZ HuRTADO, Catalina. (2007) "Una gramática local del guión audiodescrito. Desde la semántica a la pragmática de un nuevo tipo de traducción”. In: Jiménez, Catalina (ed.) Traducción y accesibilidad. Subtitulación para Sordos y audiodescripción para ciegos: nuevas modalidades de Traducción Audiovisual. Frankfurt: Peter Lang. pp 55- 80.

KRESS, Gunther \& Theo Van Leeuwen. (1990) Reading Images. Geelong: Deakin University Press.

KRUGER, Jan Louis. (2010) "Audio narration: re-narrativising film". Perspectives 18:3. pp. 231-249.

MARGOLIN, Uri. (1989) "Structuralist Approaches to Character in Narrative: the State of the Art". Semiotica 75(1-2). pp. 1-24.

LAVIOSA-BRAitHWAite, Sara. (1998) "Universals of Translation”. In: Baker, Mona (ed.) Routledge Encyclopedia of Translation Studies. London: Routledge. pp. 288-291.

Orero, Pilar \& Anna Vilaró. (2012) "Eye tracking Analysis of Minor Details in Films for Audio Description”. In: Agost, Rosa; Pilar Orero \& Elena di Giovanni (eds.) Multidisciplinarity in Audiovisual Translation. MonTI 4.

PITKÄNEN, Kari K. (2003) The Spatio-Temporal Setting in Written Narrative Fiction. A Study of Interaction between Words, Texts and Encyclopedic Knowledge in the Creation of Textual Meaning. Helsinki.

RemAel, Aline \& Gert Vercauteren. (2007) "Audio describing the exposition phase of films. Teaching students what to choose." Trans 11. pp. 73-93.

RemAel, Aline \& Gert Vercauteren. (2010) "The translation of recorded audio description from English into Dutch". Perspectives: Studies in Translatology 18:3. pp. 155-171.

RODRÍGUEZ, Ana. (2007) "Consideraciones acerca del lenguaje literario en los guiones audiodescritos”. In: Jiménez, Catalina (ed.) Traducción y accesibilidad. Subtitulación para Sordos y audiodescripción para ciegos: nuevas modalidades de Traducción Audiovisual. Frankfurt: Peter Lang. pp. 153-167.

SAlWAY, Andrew. (2007) "A Corpus-based Analysis of Audio Description". In: Díaz Cintas, Jorge, Pilar Orero \& Aline Remael (eds.) Media for All: Subtitling for the Deaf, Audio Description and Sign Language. Amsterdam: Rodopi. pp. 151-174.

SCHEFFEL, Michael. (2010) "Narrative Constitution". In: Hühn, Peter et al. (eds.) The Living Handbook of Narratology. Hamburg: Hamburg University Press. Full-text version at: $<$ hup.sub.uni-hamburg.de/lhn/index.php? title=Narrative Constitution\&oldid=827> [retrieved 14 June 2011] 
SCHMID, Wolf. (2005) Elemente der Narratologie. Berlin: de Gruyter.

SCHNEIDER, Ralf. (2001) "Towards a Cognitive Theory of Literary Character". Style 35:4. pp. 607-640.

SPERBER, Dan \& Deirdre Wilson. (1995) Relevance. Communication and Cognition. Malden: Blackwell Publishing.

THOMPSON, Kristin. (1999) Storytelling in the New Hollywood. Understanding Classical Narrative Technique. Harvard: University Press.

Toolan, Michael. "Coherence". In: Hühn, Peter et al. (eds.) The Living Handbook of Narratology. Hamburg: Hamburg University Press. Full-text version at: <hup.sub.uni-hamburg.de/lhn/index.php?title=Narrative Constitution\& oldid $=827>$ [retrieved 23 June 2011]

Vercauteren, Gert. (2010a) "The Audio Description of Space in Film. A Narratological Approach to Content Selection in AD". Paper presented at the 'Emerging Topics in Translation Studies' Conference, 16 June - 18 June 2010, Trieste.

Vercauteren, Gert. (2010b) "The Audio Description of Characters in Film. A Narratological Approach to Content Selection in AD". Paper presented at the $8^{\text {th }}$ International Languages $\&$ The Media Conference, 6 October -8 October 2010, Berlin.

Vilaró, Anna; Andrew T. Duchowski; Pilar Orero; Tom Grindinger; Stephen Tetreault \& Elena di Giovanni. (2012) "How Sound is The Pear Tree? Testing the Effect of Varying Audio Stimuli on Visual Attention Distribution". Perspectives, Special Issue on The Pear Tree Project.

ZoRan, Gabriel. (1984) "Towards a Theory of Space in Narrative". Poetics Today, 5:2. pp. 309-335.

\section{Filmography}

BOyLE, D. Slumdog Millionaire (2008). UK.

GraY, G.F Law Abiding Citizen (2009). USA.

HÅFSTRÖM, M. Derailed (2005). USA/UK.

MARSHALL, R. Memoirs of a Geisha (2005). USA.

SCORSESE, M. Shutter Island (2010). USA.

SCOTT, T. Déjà Vu (2006). USA/UK. 


\section{BIONOTE / NOTA BIOGRÁFICA}

\section{Gert Vercauteren}

Gert Vercauteren is junior lecturer and research assistant at the Department of Translators and Interpreters of Artesis University College, Antwerp, where he teaches computer-assisted translation as well as literary and audiovisual translation in the Portuguese department. His field of research is Audiovisual Translation in general and audio description in particular. He is currently preparing a $\mathrm{PhD}$ on narratology and content selection in $\mathrm{AD}$ and was involved in the European Digital Television for All-project co-ordinated by the Autonomous University of Barcelona. In 2009 he gave workshops in AD in the Summer School in Screen Translation in Forli and at the 3rd Media for All Conference in Antwerp. In 2011 he presented an advanced workshop on AD at the 4th Media for All Conference in London.

Gert Vercauteren est assistant et chargé de recherche au sein du Département Interprètes et Traducteurs de l'Haute École Artesis, Anvers. Il y enseigne la traduction assistée par ordinateur, ainsi que la traduction littéraire et audiovisuelle dans le Département de Portugais. Son domaine de recherche couvre la traduction audiovisuelle en général et la description audio en particulier. Il prépare actuellement un doctorat sur la narratologie et la sélection de contenu dans la description audio. Il a travaillé au sein de la European Digital Television for All-project, coordonnée par l'Université Autonome de Barcelone. En 2009, il a dirigé des ateliers de description audio à l'Université d'Eté pour la Traduction Audiovisuelle à Forli et à la $3^{\text {ième }}$ Conférence Media for All à Anvers. En 2011, il a présenté un atelier avancé sur la description audio à la $4^{\text {ième }}$ Conférence Media for All, à Londres. 